\section{RSP}

http://www.rsp.fsp.usp.br/
Revista de Saúde Pública

\title{
Hospital-acquired conditions and length of stay in the pregnancy and puerperal cycle
}

\author{
Thales Philipe Rodrigues da Silva' iD, Ariene Silva do Carmo' iD, Taiane Gonçalves Novaes" (iD, \\ Larissa Loures Mendes"II iD, Alexandra Dias Moreira ${ }^{\text {IV }}$ iD, Milene Cristine Pessoa"I ID, Luna \\ Cosenza $^{\mathrm{v}}$ iD, Juliana Fantini Chaves Pereira ${ }^{\mathrm{v}}$ (iD, Fernanda Penido Matozinhos ${ }^{\mathrm{IV}}$ \\ ' Universidade Federal de Minas Gerais. Faculdade de Medicina. Programa de Pós-Graduação em Ciências da \\ Saúde. Belo Horizonte, MG, Brasil \\ " Universidade Federal de Viçosa. Departamento de Nutrição. Programa de Pós-Graduação em Saúde e Nutrição \\ de Grupos Populacionais. Viçosa, MG, Brasil \\ III Universidade Federal de Minas Gerais. Escola de Enfermagem. Departamento de Nutrição. Belo Horizonte, \\ MG, Brasil \\ Iv Universidade Federal de Minas Gerais. Escola de Enfermagem. Departamento de Enfermagem Materno-Infantil \\ e Saúde Pública. Belo Horizonte, MG, Brasil \\ $\checkmark$ Instituto de Acreditação e Gestão em Saúde (IAG Saúde). Belo Horizonte, MG, Brasil
}

Correspondence:

Fernanda Penido Matozinhos Escola de Enfermagem - UFMC

Departamento de Enfermagem Materno-Infantil e Saúde Pública Av. Alfredo Balena, 190 Santa Efigênia 30130-100 Belo Horizonte, MG, Brasil E-mail: nandapenido@hotmail.com

Received: Jan 18, 2018

Approved: Oct 2, 2018

How to cite: Silva TPR, Carmo AS, Novaes TG, Mendes LL, Moreira AD, Pessoa MC, et al. Hospital-acquired conditions and length of stay in the pregnancy and puerperal cycle. Rev Saude Publica. 2019;53:64.

Copyright: This is an open-access article distributed under the terms of the Creative Commons Attribution License, which permits unrestricted use, distribution, and reproduction in any medium, provided that the original author and source are credited.

\section{ABSTRACT}

OBJECTIVE: To analyze the impact of the Hospital-Acquired Conditions (HAC) in women in the puerperal and pregnancy cycle during length of stay.

METHODS: This cross-sectional study was conducted with 113,456 women, between July 2012 and July 2017, in Brazil's national hospitals of the supplementary healthcare networks and philanthropists accredited to the Unified Health System (SUS). Data on hospital discharges were collected using the Diagnosis-Related Groups (DRG Brasil ${ }^{\circledR}$ ) system. All DRGs of the major diagnostic category 14 (MDC14), including pregnancy, childbirth and puerperium, were included. The impact of HAC on length of stay was estimated by Student's t-test, and the effect size by Cohen's d, which allows to assess clinical relevance.

RESULTS: The most prevalent diagnostic categories related to MDC14 were vaginal and cesarean deliveries without complicating diagnoses, both at institutions accredited to SUS and those for supplementary health care. The prevalence of HAC was $3.8 \%$ in supplementary health and $2.5 \%$ in SUS. Hospitals providing services to supplementary health care providers had a longer length of stay considering HAC for patients classified as DRG: cesarean section with complications or comorbidities at admission $(p<0.001$; Cohen's $d=0.74)$, cesarean section without complications or comorbidities at admission $(p<0.001$, Cohen's $d=0.31)$, postpartum and post abortion without listed procedure $(\mathrm{p}<0.001$, Cohen's $\mathrm{d}=1.05)$, and other antepartum diagnoses with medical complications ( $\mathrm{p}<0.001$; Cohen's $\mathrm{d}=0.77$ ).

CONCLUSIONS: This study showed that the prevalence of HAC was low both in the institutions accredited to attend by SUS and in those of supplementary health; however, its presence contributes to increasing the length of stay in cases of cesarean sections without complications or comorbidities in supplementary health institutions.

DESCRIPTORS: Pregnant Women. Puerperal Disorders. Hospitalization. Length of Stay, economics. Hospital Costs. 


\section{INTRODUCTION}

Hospital-acquired conditions ((HAC) are undesirable or adverse events that directly affect the patient's health and experience in hospital care ${ }^{1}$. They refer to the medical conditions or complications developed during the hospitalization period that were not present at the time of admission ${ }^{1}$. Generally, they result in additional costs, generated both by the increase in hospital stay and by the subsequent treatments ${ }^{2}$. The stay of patients with HAC is, on average, almost four times greater than that of patients without such complications ${ }^{3}$.

Regarding the length of hospitalization, analyses estimate that the average cost of one day of hospitalization in an acute care hospital (with an average hospitalization period of less than 30 days) is $€ 371^{4}$. A study that aimed to estimate the daily costs associated with extra hospitalization time to treat HAC, specifically infections, demonstrated that they went from 1.79 to 6.91 days for neurological patients, from 3.76 to 11.3 days for patients attended in the gynecological service and, in the general average, from 0.91 to 8.09 days ${ }^{5}$. We emphasize that length of stay is an indicator of hospital efficiency and is related to the quality of care provided 6 .

Another factor that can contribute to the increase in costs to health, caused by the increase in length of stay, is the adverse event (AE), which may be an $\mathrm{HAC}^{7,8}$. The World Health Organization (WHO) defines AE as damage caused by the procedure or complication related to treatment, unrelated to the diagnosis of admission, resulting in prolonged hospitalization or disability present at the time of hospital discharge ${ }^{8}$.

A study conducted in the United States estimated that the total annual cost with AE was U\$985 million in 2008 and more than U\$ 1 billion in 2009. The average cost per AE for hospitals was U\$ 892 in 2008 and increased to U\$ 939 in $2009^{9}$. In Europe, the AEs considered as preventable events represented a total expenditure of $€ 277,665^{10}$.

In Brazil, a study that aimed to estimate the financial resources spent on patients with $\mathrm{AE}$ in hospitals showed that the mean value per patient with $\mathrm{AE}$ considered avoidable (R\$ 1,270.47) was 19.5\% higher than the mean value per patient without AE. Considering all AEs, the mean value for treating these patients (R\$3,195.42) was $200.5 \%$ higher than that for patients without $\mathrm{AE}^{7}$.

The economic impacts of $\mathrm{HAC}$ are already well established in the literature ${ }^{4,5,7,9,10}$. However, new studies are necessary to evaluate the economic impact and length of stay in specific populations, especially women in the pregnancy and puerperal cycle. By 2015, about 303,000 women and adolescents died as a result of complications related to pregnancy and childbirth. It is noteworthy that $99 \%$ of these maternal deaths occur in contexts of low resources and the majority could be prevented ${ }^{11}$. In Brazil, maternal mortality has declined in recent years, but remains high compared to high-income countries ${ }^{12}$.

The assessment of the impact of HAC on this population may contribute to the improvement of programs that prevent or minimize the occurrence of conditions acquired in the hospital during this period of the reproductive cycle, thus favoring a better quality of care and avoiding potentially fatal complications. Given this problem, the objective of this study was to analyze the impact of the Hospital-Acquired Conditions in women in the pregnancy and puerperal cycle on the length of stay.

\section{METHODS}

This is an epidemiological study with a cross-sectional design, held with 113,456 women between July 2012 and July 2017, in private hospitals that provide services to supplementary health care providers in Brazil and to the Unified Health System (SUS), distributed in all regions of the country and that use Diagnosis-Related Groups (DRG Brasil ${ }^{\circledR}$ version 9). The 
data were collected from the medical records after discharge and registered in the DRG Brasil $^{\circledR}$ system by nurses dedicated to this function.

DRG or Diagnostic-Related Groups is a methodology for categorizing patients into homogeneous groups according to their characteristics and complexity of treatment. It is applicable to patients admitted to hospitals that attend acute cases, that is, those in which the average hospitalization of the patient does not exceed 30 days $^{13}$. For classification of cases into groups, the following variables are considered: principal diagnosis, patient's age and sex; comorbidities and complications (secondary diagnoses); and surgical procedures performed ${ }^{14,15}$. For describing the principal, secondary and acquired diagnoses, the International Classification of Diseases (ICD-10) was used. The procedures performed were coded according to the tables used in the SUS and supplementary health (in this case, the Supplementary Healthcare Unified Terminology - TUSS).

Data collection on HAC occurred in two instances: in DRG coders, by reading the medical records and posting the information in DRG Brasil, and by services of care security and hospital infection control, which had been working for years with active search for infectious and non-infectious events in these institutions, in addition to reports of adverse events.

All DRGs that make up the major diagnostic category 14 (MDC14), which includes pregnancy, childbirth and puerperium were included, totaling 15 DRGs (765 to 782). The economic impact was measured indirectly by the variable length of stay, in days.

The sample was described by absolute and relative frequencies. Mean, standard deviation (SD), confidence interval of averages and percentiles of interest (p10, p25, p50, p75 and p90) were presented in relation to the length of stay. The results were presented considering the DRG and the paying source (supplementary health or SUS). In addition, statistics were calculated for the overall length of hospital stay, considering whether acquired conditions occurred or not.

The comparative analysis between two groups of patients (with and without HAC) regarding the stay for each DRG was performed using Student's t-test for independent

Table 1. Characterization of payment source and most frequent DRGs of the diagnostic categories related to pregnancy, childbirth and puerperium. Brazil, 2012-2017.

\begin{tabular}{|c|c|c|c|c|c|}
\hline \multicolumn{2}{|r|}{ Diagnostic categories } & \multicolumn{4}{|c|}{ Payment source } \\
\hline \multirow{2}{*}{ DRG } & \multirow{2}{*}{ Description } & \multicolumn{2}{|c|}{ Public service } & \multicolumn{2}{|c|}{ Supplementary health } \\
\hline & & $\mathrm{n}$ & $\%$ & $\mathrm{n}$ & $\%$ \\
\hline 765 & Cesarean section with $\mathrm{CC} / \mathrm{MCC}$ & 1,036 & 7.83 & 12,252 & 12.22 \\
\hline 766 & Cesarean section without CC/MCC & 3,990 & 30.17 & 49,707 & 49.59 \\
\hline 767 & Vaginal delivery with sterilization and/or dilation and curettage & 70 & 0.53 & 419 & 0.42 \\
\hline 768 & Vaginal delivery with O.R. procedure except sterilization and/or dilatation and curettage & 2 & 0.02 & 17 & 0.02 \\
\hline 769 & Postpartum and post abortion diagnoses with O.R. procedure & 146 & 1.10 & 432 & 0.43 \\
\hline 770 & Abortion with dilation and curettage, aspiration curettage or hysterectomy & 743 & 5.62 & 8,331 & 8.31 \\
\hline 774 & Vaginal delivery with complicating diagnoses & 204 & 1.54 & 858 & 0.86 \\
\hline 775 & Vaginal delivery without complicating diagnoses & 6,055 & 45.78 & 21,694 & 21.64 \\
\hline 776 & Postpartum and post abortion diagnoses without listed procedure & 97 & 0.73 & 671 & 0.67 \\
\hline 777 & Ectopic pregnancy & 88 & 0.67 & 1,100 & 1.10 \\
\hline 778 & Threatened abortion & 123 & 0.93 & 1,033 & 1.03 \\
\hline 779 & Abortion without dilatation and curettage & 21 & 0.16 & 323 & 0.32 \\
\hline 780 & False labor & 33 & 1.25 & 199 & 0.20 \\
\hline 781 & Other antepartum diagnoses with medical complications & 317 & 2.40 & 2,135 & 2.13 \\
\hline 782 & Other antepartum diagnoses without medical complications & 302 & 2.28 & 1,058 & 1.06 \\
\hline Total & & 13,227 & & 100,229 & \\
\hline
\end{tabular}

DRG: Diagnosis-Related Groups; CC: complications or comorbidities at admission; MCC: major complications or comorbidities (very significant), additional to initial diagnosis 
samples. In cases where the analysis indicated a significant difference $(\mathrm{p}<0.05)$, the size of this effect was evaluated. Because these are large samples, there is an increase in the probability of type I error; therefore, effect size measurement by Cohen's D allows the evaluation of clinical relevance. Thus, only factors with a significant effect and effect size equal to or greater than 0.30 were considered. Data were processed and analyzed using the free software R.

The project was approved by the Research Ethics Committee, number 34133814.5.0000.5149. Exemption from the free and informed consent form was obtained.

\section{RESULTS}

Among the diagnostic categories related to pregnancy, childbirth and puerperium, vaginal delivery without complicating diagnoses (DRG 775) was the most prevalent in public care (45.8\%). On the other hand, in supplementary health, cesarean section without complications or comorbidities at admission (DRG 766) was the most prevalent (49.6\%) (Table 1).

Cesarean sections with and without complications at admission represented more than half $(61.8 \%)$ of all prevalent hospitalizations / in supplementary health, being present in $38.0 \%$ of cases in public care. In relation to vaginal deliveries with or without complications, the prevalence of hospitalization was $47.9 \%$ in public care and $22.9 \%$ in supplementary health (Table 1).

Table 2. Characterization of hospitalizations in public service in relation to the stay according to the diagnostic category related to pregnancy, childbirth and puerperium. Brazil, 2012-2017.

\begin{tabular}{|c|c|c|c|c|c|c|c|c|}
\hline \multicolumn{9}{|c|}{ Public service } \\
\hline DRG & $n$ & $\bar{x}(\mathrm{DP})$ & $\mathrm{Cl95} \%(\bar{x})$ & p10 & p25 & p50 & p75 & p90 \\
\hline \multicolumn{9}{|c|}{ Overall length of stay (days) } \\
\hline 765 & 1,036 & $3.8(1.8)$ & $3.69-3.91$ & 2.1 & 2.6 & 3.1 & 4.8 & 9.0 \\
\hline 766 & 3,990 & $2.8(1.4)$ & $2.76-2.84$ & 2.1 & 2.2 & 2.8 & 3.1 & 4.0 \\
\hline 767 & 70 & $2.2(1.7)$ & $1.80-2.60$ & 1.2 & 1.5 & 2.1 & 3.0 & 4.5 \\
\hline 769 & 146 & $3.1(1.8)$ & $2.81-3.39$ & 1.7 & 3.0 & 3.0 & 3.0 & 6.3 \\
\hline 770 & 743 & $1.1(1.7)$ & $0.98-1.22$ & 0.6 & 0.8 & 1.0 & 1.5 & 2.0 \\
\hline 774 & 204 & $2.8(1.7)$ & $2.57-3.03$ & 1.6 & 1.9 & 2.7 & 3.6 & 5.6 \\
\hline 775 & 6,055 & $2.0(1.4)$ & $1.96-2.04$ & 1.3 & 1.5 & 1.9 & 2.4 & 3.0 \\
\hline 776 & 97 & $2.9(2.2)$ & $2.46-3.34$ & 1.1 & 1.7 & 2.7 & 5.0 & 7.9 \\
\hline 777 & 88 & $2.5(1.6)$ & $2.17-2.83$ & 1.7 & 1.9 & 2.2 & 2.9 & 4.5 \\
\hline 778 & 123 & $2.0(2.5)$ & $1.56-2.44$ & 0.6 & 1.0 & 2.5 & 3.7 & 5.0 \\
\hline 780 & 33 & $1.5(2.3)$ & $0.72-2.28$ & 0.7 & 0.9 & 1.4 & 2.5 & 4.1 \\
\hline 781 & 317 & $3.0(2.1)$ & $2.77-3.23$ & 1.2 & 1.9 & 2.8 & 4.7 & 7.8 \\
\hline 782 & 302 & $2.9(2.2)$ & $2.65-3.15$ & 1.1 & 1.8 & 3.0 & 4.6 & 7.8 \\
\hline \multicolumn{9}{|c|}{ Length of stay excluding Hospital- Acquired Conditions - (days) } \\
\hline 765 & 1,018 & $3.8(1.8)$ & $3.69-3.91$ & 2.1 & 2.6 & 3.0 & 4.7 & 8.8 \\
\hline 766 & 3,980 & $2.8(1.4)$ & $2.76-2.84$ & 2.1 & 2.2 & 2.8 & 3.1 & 4.0 \\
\hline 767 & 59 & $2.3(1.8)$ & $1.84-2.76$ & 1.2 & 1.5 & 2.2 & 3.0 & 5.3 \\
\hline 769 & 145 & $3.1(1.7)$ & $2.82-3.38$ & 1.7 & 3.0 & 3.0 & 3.0 & 5.5 \\
\hline 770 & 742 & $1.1(1.7)$ & $0.98-1.22$ & 0.6 & 0.8 & 1.0 & 1.5 & 2.0 \\
\hline 774 & 186 & $2.8(1.7)$ & $2.56-3.04$ & 1.6 & 1.9 & 2.7 & 3.6 & 5.2 \\
\hline 775 & 5,791 & $2.0(1.5)$ & $1.96-2.04$ & 1.3 & 1.5 & 1.9 & 2.4 & 3.0 \\
\hline 776 & 94 & $2.9(2.2)$ & $2.46-3.34$ & 1.0 & 1.7 & 2.7 & 5.0 & 7.9 \\
\hline 777 & 88 & $2.5(1.6)$ & $2.17-2.83$ & 1.7 & 1.9 & 2.2 & 2.9 & 4.5 \\
\hline 778 & 123 & $2.0(2.5)$ & $1.56-2.44$ & 0.6 & 1.0 & 2.5 & 3.7 & 5.0 \\
\hline 780 & 33 & 1.5 & $0.72-2.28$ & 0.7 & 0.9 & 1.4 & 2.5 & 4.1 \\
\hline 781 & 315 & $2.9(2.1)$ & $2.67-3.13$ & 1.2 & 1.9 & 2.8 & 4.7 & 7.8 \\
\hline 782 & 299 & $2.9(2.2)$ & $2.65-3.15$ & 1.1 & 1.8 & 3.0 & 4.6 & 7.8 \\
\hline
\end{tabular}

DRG: Diagnosis-Related Groups 
HAC occurred in $3.8 \%$ of hospitalizations in supplementary health and $2.5 \%$ in public care. Among HAC by women in the pregnancy and puerperal cycle, the most prevalent in supplementary healthcare services were: second degree perineal laceration during delivery (20.3\%), infection of obstetric surgical wound (9.4\%), delayed and secondary postpartum hemorrhage (8.2\%), and spinal and epidural anesthesia-induced headache during the puerperium (7.4\%). In public service, the most frequent acquired conditions were perineal lacerations during delivery, with those of second degree corresponding to $73.4 \%$ of the cases $-5.7 \%$ were first degree and $4.2 \%$ third degree (data not shown).

Regarding the overall length of stay and length of hospitalization, excluding the HAC, the cesarean section with complications or comorbidities at admission (DRG 765) was responsible for the highest rates for public care, with a mean of 3.8 days (CI95\% 3.69-3.91) in both indicators (Table 2). In supplementary health, cesarean section with complications or comorbidities at admission and postpartum and post abortion diagnoses without O.R. procedure (DRG 776) were responsible for a longer hospitalization (Table 3).

Table 3. Characterization of hospitalizations of supplementary health in relation to stay due to diagnostic category related to pregnancy, childbirth and puerperium. Brazil, 2012-2017.

\begin{tabular}{|c|c|c|c|c|c|c|c|c|}
\hline \multicolumn{9}{|c|}{ Supplementary health } \\
\hline DRG & $\mathbf{n}$ & $\bar{x}(d p)$ & $\mathrm{Cl} 95 \%(\bar{x})$ & p10 & p25 & p50 & p75 & p90 \\
\hline \multicolumn{9}{|c|}{ Overall length of stay (days) } \\
\hline 765 & 12,252 & $2.6(1.7)$ & $2.57-2.63$ & 1.7 & 2.0 & 2.2 & 3.0 & 5.2 \\
\hline 766 & 49,707 & $2.2(1.3)$ & $2.19-2.21$ & 1.7 & 1.9 & 2.1 & 2.3 & 2.9 \\
\hline 767 & 419 & $2.0(1.9)$ & $1.82-2.18$ & 1.1 & 1.4 & 1.9 & 2.6 & 4.5 \\
\hline 769 & 432 & $1.5(3.5)$ & $1.17-1.83$ & 0.3 & 0.7 & 1.6 & 3.2 & 7.7 \\
\hline 770 & 8,331 & $0.7(2.1)$ & $0.65-0.75$ & 0.3 & 0.4 & 0.7 & 1.0 & 1.5 \\
\hline 774 & 858 & $2.3(1.8)$ & $2.18-2.42$ & 1.3 & 1.6 & 2.1 & 2.7 & 4.1 \\
\hline 775 & 21,694 & $1.8(1.5)$ & $1.78-1.82$ & 1.2 & 1.4 & 1.8 & 2.2 & 2.7 \\
\hline 776 & 671 & $2.7(2.4)$ & $2.52-2.88$ & 0.8 & 1.7 & 2.9 & 4.7 & 7.1 \\
\hline 777 & 1,100 & $1.6(1.7)$ & $1.50-1.70$ & 0.8 & 1.1 & 1.7 & 2.0 & 2.8 \\
\hline 778 & 1,033 & $1.9(2.4)$ & $1.75-2.05$ & 0.6 & 1.1 & 1.8 & 3.0 & 5.5 \\
\hline 779 & 323 & $1.1(2.4)$ & $0.84-1.36$ & 0.4 & 0.7 & 1.1 & 1.9 & 3.0 \\
\hline 780 & 199 & $1.3(2.6)$ & $0.94-1.66$ & 0.4 & 0.7 & 1.6 & 2.4 & 3.9 \\
\hline 781 & 2,135 & $2.2(2.2)$ & $2.11-2.29$ & 0.8 & 1.4 & 2.3 & 3.7 & 5.7 \\
\hline 782 & 1,058 & $2.3(2.4)$ & $2.16-2.44$ & 0.8 & 1.4 & 2.2 & 3.9 & 6.9 \\
\hline \multicolumn{9}{|c|}{ Length of stay excluding Hospital- Acquired Conditions (days) } \\
\hline 765 & 11,453 & $2.6(1.6)$ & $2.57-2.63$ & 1.7 & 2.0 & 2.2 & 2.9 & 4.8 \\
\hline 766 & 48,581 & $2.1(1.3)$ & $2.09-2.11$ & 1.7 & 1.9 & 2.1 & 2.3 & 2.8 \\
\hline 767 & 331 & $2.0(1.9)$ & $1.80-2.20$ & 1.0 & 1.4 & 1.9 & 2.6 & 4.2 \\
\hline 769 & 404 & $1.4(3.3)$ & $1.08-1.72$ & 0.3 & 0.7 & 1.5 & 3.0 & 6.3 \\
\hline 770 & 8,273 & $0.7(2.1)$ & $0.65-0.75$ & 0.3 & 0.4 & 0.7 & 1.0 & 1.5 \\
\hline 774 & 777 & $2.2(1.8)$ & $2.07-2.33$ & 1.3 & 1.6 & 2.1 & 2.7 & 4.1 \\
\hline 775 & 20,214 & $1.8(1.5)$ & $1.78-1.82$ & 1.2 & 1.4 & 1.7 & 2.2 & 2.7 \\
\hline 776 & 639 & $2.6(2.4)$ & $2.41-2.79$ & 0.8 & 1.7 & 2.9 & 4.7 & 6.8 \\
\hline 777 & 1,079 & $1.6(1.7)$ & $1.50-1.70$ & 0.8 & 1.1 & 1.7 & 2.0 & 2.8 \\
\hline 778 & 1,016 & $1.8(2.4)$ & $1.65-1.95$ & 0.6 & 1.1 & 1.8 & 2.9 & 5.3 \\
\hline 779 & 322 & $1.1(2.4)$ & $0.84-1.36$ & 0.4 & 0.7 & 1.1 & 1.8 & 3.0 \\
\hline 780 & 198 & $1.3(2.6)$ & $0.94-1.66$ & 0.4 & 0.7 & 1.6 & 2.4 & 3.9 \\
\hline 781 & 2,072 & $2.2(2.2)$ & $2.11-2.29$ & 0.8 & 1.4 & 2.2 & 3.6 & 5.6 \\
\hline 782 & 1,050 & $2.3(2.4)$ & $2.15-2.45$ & 0.8 & 1.4 & 2.2 & 3.9 & 6.9 \\
\hline
\end{tabular}

DRG: Diagnosis-Related Groups 
Table 4. Comparative analysis between group of patients with Hospital- Acquired Conditions and group of patients without acquired conditions in relation to the stay (in days), in supplementary health. Brazil, 2012-2017.

\begin{tabular}{|c|c|c|c|c|c|c|c|c|}
\hline \multirow{2}{*}{ DRG } & \multicolumn{3}{|c|}{ With Hospital- Acquired Conditions } & \multicolumn{3}{|c|}{ Without Hospital- Acquired Conditions } & \multirow{2}{*}{$\mathbf{p}$} & \multirow{2}{*}{$\begin{array}{l}\text { Cohen's } \\
\text { d }\end{array}$} \\
\hline & n & $\bar{x}(d p)$ & $95 \% \mathrm{Cl}(\bar{x})$ & $\mathbf{n}$ & $\bar{x}(d p)$ & $95 \% \mathrm{Cl}(\bar{x})$ & & \\
\hline 765 & 799 & $3.8(2.0)$ & $3.64-3.93$ & 11,453 & $2.6(1.6)$ & $2.57-2.63$ & $<0.001$ & 0.74 \\
\hline 766 & 1,126 & $2.5(1.5)$ & $2.45-2.63$ & 48,581 & $2.1(1.3)$ & $2.09-2.11$ & $<0.001$ & 0.31 \\
\hline 767 & 88 & $2.3(1.8)$ & $1.96-2.71$ & 331 & $2.0(1.9)$ & $1.80-2.20$ & 0.018 & 0.16 \\
\hline 770 & 57 & $1.2(2.9)$ & $0.45-1.97$ & 8,273 & $0.7(2.1)$ & $0.65-0.75$ & 0.001 & 0.24 \\
\hline 774 & 81 & $2.5(1.8)$ & $2.07-2.83$ & 777 & $2.2(1.8)$ & $2.07-2.33$ & 0.142 & 0.17 \\
\hline 775 & 1,480 & $1.9(1.5)$ & $1.83-1.98$ & 20,214 & $1.8(1.5)$ & $1.78-1.82$ & $<0.001$ & 0.07 \\
\hline 776 & 32 & $5.1(2.1)$ & $4.42-5.84$ & 639 & $2.6(2.4)$ & $2.41-2.79$ & $<0.001$ & 1.05 \\
\hline 781 & 63 & $3.9(2.0)$ & $3.44-4.42$ & 2,072 & $2.2(2.2)$ & $2.11-2.29$ & $<0.001$ & 0.77 \\
\hline
\end{tabular}

DRG: Diagnosis-Related Groups

p-value in bold $<0.05$ according to Student's t-test for independent samples.

Table 4 presents a comparative analysis between groups of patients from supplementary health with and without acquired conditions. We observed a longer hospital stay in the presence of AHC for patients categorized in DRG: cesarean section with complications or comorbidities at admission (DRG 765); cesarean section without complications or comorbidities at admission (DRG 766); vaginal delivery with sterilization and/or dilatation and curettage (DRG 767); abortion with dilation and curettage, aspiration curettage or hysterectomy (DRG 770); vaginal delivery without complicating diagnoses (DRG 775); postpartum and post abortion diseases without O.R. procedure (DRG 776); and other antepartum diagnoses with medical complications (DRG 781). When analyzing Cohen's d values, the HAC were related to a longer hospital stay in DRG 765 (3.8 days versus 2.6 days, $p<0.001$, Cohen's $d=0.74)$, DRG 766 (2.5 days versus 2.1 days, $p<0.001$, Cohen's $d=0.31$ ), DRG 776 (5.1 days versus 2.6 days, $\mathrm{p}<0.001$, Cohen's $\mathrm{d}=1.05$ ), and DRG 781 (3.9 days versus 2.2 days, $\mathrm{p}<0.001$, Cohen's $\mathrm{d}=0.77$ ).

We emphasize that, for the other supplementary health categories, as well as for all categories of public care, no differences were found between the overall length of stay and length of hospitalization, excluding the acquired conditions.

\section{DISCUSSION}

This study showed that the most prevalent diagnostic categories related to pregnancy, childbirth and puerperium were vaginal deliveries without complicating diagnoses and cesarean sections, both in public and supplementary health care institutions. The $\mathrm{HAC}$ increased the length of stay in cases of cesarean section with complications or comorbidities at admission, cesarean section without complications or comorbidities at admission, pospartum and post abortion diseases without O.R. procedure, and other antepartum diagnoses with medical complications in the hospitals that provide services to supplementary health care providers in Brazil.

Cesarean sections with complications or comorbidities at admission are among the DRGs that most contributed to the longest period of hospitalization, with an average of 3.8 and 2.6 days in the public and private sectors, respectively. Studies show that the length of hospital stay for cesarean sections is higher than for vaginal delivery ${ }^{16}$. One of the probable reasons for this difference is the slow wound healing process and the long period of convalescence in cesarean sections ${ }^{16}$. The prolonged hospitalization time of cesarean sections is one of the factors that contributes to the higher hospital cost of this procedure ${ }^{14}$. 
According to the WHO, cesarean rates above $10 \%$ are not associated with the reduction of maternal and neonatal mortality, and this practice should be performed only when necessary ${ }^{15}$. The rates of cesarean sections found in this study, both in supplementary health (72.94\%) and in public care (44.25\%), are higher than those recommended by the WHO.

Rates of cesarean deliveries increased considerably in several countries ${ }^{17}$. In Brazil, it was $15 \%$ in the 1970s, 30\% in the early 1980s, reached $40 \%$ in the early 1990s, and stabilized in the $2000 \mathrm{~s}^{18}$. According to data from the study "Birth in Brazil: national enquiry into labor and birth" from 2011-2012, the cesarean rate in the private sector is higher than that found in the public sector ( $87.9 \%$ versus $42.9 \%$, respectively) ${ }^{19}$. There are several factors that favor the increase of cesarean sections, especially in the private sector, such as: financial reimbursement offered by Brazilian supplementary health insurance, infrastructure issues, qualification human resources, cultural factors and maternal request ${ }^{20,21}$.

We can infer that in the private sector, cesarean sections are not predominantly related to the presence of obstetric risk, since rates are high in low-risk women ${ }^{19}$. In addition, around $84.2 \%$ of all cesarean sections in Brazil are performed before the active stage of labor ${ }^{19}$. This scenario may contribute to increased maternal and neonatal morbidity and mortality, especially when surgery is performed before 39 weeks of gestational age ${ }^{22}$.

Given this context, in 2016, the Federal Medical Council (CFM) established criteria for cesarean section at the request of women in Brazil. It established that, in situations of habitual risk, it could be performed only from the 39th week of gestation ${ }^{23}$. In addition, the National Regulatory Agency for Private Health Insurance and Plans (ANS) implemented some measures to encourage normal childbirth, such as mandatory use of the partograph and the pregnant woman's card. The same resolution determines the right of access of the population to the percentage of cesarean sections performed by a health plan, establishment and physician ${ }^{24}$. However, it is crucial to think of other institutional and organizational strategies of the health care networks, seeking changes in the paradigm of obstetric care, in order to conduct the birth process more physiologically ${ }^{25,26}$ and, consequently, reduce unnecessary hospital expenses and conditions acquired in the pregnancy and puerperal cycle.

We emphasize that in our study, the HAC with the cesarean section without complication or comorbidity increased the length of hospital stay in the supplementary health sector, being more frequent conditions the infections of surgical wounds, hemorrhages in the immediate postpartum, lacerations and headache related to anesthetic procedure. Besides increasing hospital costs, elective cesarean sections are associated with an increased risk of maternal mortality and severe obstetric complications ${ }^{27}$.

A recent meta-analysis evaluated acute maternal complications related to cesarean sections without indication. Women who underwent cesarean deliveries had nearly a threefold increase in the chance of infection compared to those undergoing vaginal delivery, and a greater chance of being admitted to an intensive care unit. On the other hand, vaginal deliveries have a greater chance of obstetric trauma and bleeding, however with degree of weak evidence ${ }^{28}$.

Postpartum hemorrhage is the main cause of maternal mortality in the world ${ }^{29}$, besides predicting other complications, such as acute renal failure and disseminated intravascular coagulation. Health professionals should therefore be familiar with identifying the causes of hemorrhage (uterine atony, lacerations, retained placenta) and their respective procedures, such as administration of uterotonics ${ }^{30}$.

The coincidence between length of stay and length of hospitalization excluding the HAC in the other DRGs may be due to the low prevalence (less than 5\%) of adverse conditions observed among the women evaluated. Another finding of this study is that the impact of a longer stay on women in the pregnancy and puerperal cycle is associated with higher costs for services. The reduction of hospital costs has become a constant concern among health 
administrators ${ }^{31}$. Hospital institutions began to pay attention to this aspect, but trying to maintain an excellent service and ensure customer satisfaction; to that end, patient safety was established as the main objective ${ }^{32}$. Therefore, the literature emphasizes that HAC may be a result of problems in practice, products, processes or systems, and that their occurrence results from a chain of systemic factors ${ }^{1-3}$. We reinforce that studies in hospitals in several countries show the association between HAC and increased length of stay, one of the patient safety indicators ${ }^{3,6,33,34}$.

As limitations, the study presents low sample representativeness of the public sector, making impossible the statistic comparison of confidence intervals of the averages of public health care and those of supplementary health. Another limitation is the lack of information on the remuneration mechanism, which is known to influence the length of stay of women and the coding quality of the HAC. We should also highlight the potential issues of the study, such as the use of data from the DRG system, which presents good representation for supplementary health.

This study showed low prevalence of HAC, contributing to the increase of length of stay in cases of cesarean sections without complications or comorbidities in supplementary health. These data suggest the need for strategies that recommend surgical procedure through precise indications, considering clinical and obstetric criteria, which may contribute to greater safety and protection of maternal and neonatal health, as well as the optimization of hospital expenses.

\section{REFERENCES}

1. Bohlouli B, Jackson TJ, Tonelli M, Hemmelgarn B, Klarenbach S. Adverse outcomes associated with preventable complications in hospitalized patients with CKD. Clin J Am Soc Nephrol. 2017;12(5):799-806. https://doi.org/10.2215/CJN.09410916

2. Kandilov A, Coomer NM, Dalton K. The impact of hospital-acquired conditions on Medicare program payments. Medicare Medicaid Res Rev. 2014;4(4):E1-23. https://doi.org/10.5600/mmrr.004.04.a01

3. Trentino KM, Swain SG, Burrows SA, Sprivulis PC, Daly FFS. Measuring the incidence of hospital-acquired complications and their effect on length of stay using CHADx. Med J Aust. 2013;199(8):543-7. https://doi.org/10.5694/mja12.11640

4. Vrijens F, Hulstaert F, Devriese S, Van de Sande S. Hospital-acquired infections in Belgian acute-care hospitals: an estimation of their global impact on mortality, length of stay and healthcare costs. Epidemiol Infect. 2012;140(1):126-36. https://doi.org/10.1017/S0950268811000100

5. Arefian H, Hagel S, Heublein S, Rissner F, Scherag A, Brunkhorst FM, et al. Extra length of stay and costs because of health care-associated infections at a German university hospital. Am J Infect Control. 2016;44(2):160-6. https://doi.org/10.1016/j.ajic.2015.09.005

6. Silva AMN, Souza EFD, Andrade-Barbosa TL, Silva CSO, Gomes LMX. Factors that contribute to prolonged length of stay in the hospital environment. Cuidado é Fundamental. 2014;6(4):1590. https://doi.org/10.9789/2175-5361.2014.v6i4.1590-1600

7. Porto S, Martins M, Mendes W, Travassos C. A magnitude financeira dos eventos adversos em hospitais no Brasil. Rev Port Saude Publica. 2010 [cited 16 Jan 2018];10(10):74-80. Available from: http://www.elsevier.pt/pt/revistas/revista-portuguesa-saude-publica-323/artigo/amagnitude-financeira-dos-eventos-adversos-em-hospitais-X0870902510898606

8. World Health Organization. The conceptual framework for the International Classification for Patient Safety version 1.1: final technical report. Geneva: WHO; 2010 [cited 16 Jan 2018]. Available from: https://apps.who.int/iris/handle/10665/70882

9. David G, Gunnarsson CL, Waters HC, Horblyuk R, Kaplan HS. Economic measurement of medical errors using a hospital claims database. Value Health. 2013;16(2):305-10. https://doi.org/10.1016/j.jval.2012.11.010

10. Magdelijns FJH, Stassen PM, Stehouwer CDA, Pijpers E. Direct health care costs of hospital admissions due to adverse events in the Netherlands. Eur J Public Health. 2014;24(6):1028-33. https://doi.org/10.1093/eurpub/cku037 
11. Alkema L, Chou D, Hogan D, Zhang S, Moller AB, Gemmill A, et al. Global, regional, and national levels and trends in maternal mortality between 1990 and 2015, with scenario-based projections to 2030: a systematic analysis by the UN Maternal Mortality Estimation Inter-Agency Group. Lancet. 2016;387(10017):462-74. https://doi.org/10.1016/S0140-6736(15)00838-7

12. Lozano R, Wang H, Foreman KJ, Rajaratnam JK, Naghavi M, Marcus JR, et al. Progress towards Millennium Development Goals 4 and 5 on maternal and child mortality: an updated systematic analysis. Lancet. 2011;378(9797):1139-65. https://doi.org/10.1016/S0140-6736(11)61337-8

13. Palmer GR, Freeman JL, Fetter RB, Mador M. International comparisons of hospital usage: a study of nine countries, based on DRGs. New Haven, CT: Yale School of Organization and Management, Health Systems Management Group; 1989.

14. Yang YT, Mello MM, Subramanian SV, Studdert DM. Relationship between malpractice litigation pressure and rates of cesarean section and vaginal birth after cesarean section. Med Care. 2009;47(2):234-42. https://doi.org/10.1097/M R.0b013e31818475de

15. Organização Mundial da Saúde, Departamento de Saúde Reprodutiva e Pesqisa. Programa de Reprodução Humana. Declaração da OMS sobre Taxas de Cesáreas. Genebra: OMS; 2015 [cited 28 Jan 2018]. Available from: http://apps.who.int/iris/bitstream/handle/10665/161442/ WHO_RHR_15.02_por.pdf; jsessionid=EBF63A5AF9B95398311AF1C44E9E62B5? sequence=3

16. He Z, Cheng Z, Wu T, Zhou Y, Chen J, Fu Q, et al. The costs and their determinant of cesarean section and vaginal delivery: an exploratory study in Chongqing Municipality, China. Biomed Res Int. 2016:5685261. https://doi.org/10.1155/2016/5685261

17. Villar J, Valladares E, Wojdyla D, Zavaleta N, Carroli G, Velazco A, et al. Caesarean delivery rates and pregnancy outcomes: the 2005 WHO global survey on maternal and perinatal health in Latin America. Lancet. 2006;367(9525):1819-29. https://doi.org/10.1016/S0140-6736(06)68704-7

18. Victora CG, Aquino EM, Leal MC, Monteiro CA, Barros FC, Szwarcwald CL. Maternal and child health in Brazil: progress and challenges. Lancet. 2011;377(9780):1863-76. https://doi.org/10.1016/S0140-6736(11)60138-4

19. Nakamura-Pereira M, Leal MC, Esteves-Pereira AP, Domingues RMSM, Torres JA, Dias $M A B$, et al. Use of Robson classification to assess cesarean section rate in Brazil: the role of source of payment for childbirth. Reprod Health. 2016;13 Suppl 3:128. https://doi.org/10.1186/s12978-016-0228-7

20. Ramires de Jesus G, Ramires de Jesus N, Peixoto-Filho FM, Lobato G. Caesarean rates in Brazil: What is involved? BJOG. 2015;122(5):606-9. https://doi.org/10.1111/1471-0528.13119

21. Bettes BA, Coleman VH, Zinberg S, Spong CY, Portnoy B, DeVoto E, et al. Cesarean delivery on maternal request: obstetrician-gynecologists' knowledge, perception, and practice patterns. Obstet Gynecol. 2007;109(1):57-66. https://doi.org/10.1097/01.AOG.0000249608.11864.b6

22. Souza J, Gülmezoglu A, Lumbiganon P, Laopaiboon M, Carroli G, Fawole B, et al. Caesarean section without medical indications is associated with an increased risk of adverse short-term maternal outcomes: the 2004-2008 WHO Global Survey on Maternal and Perinatal Health. BMC Med. 2010;8(1):71. https://doi.org/10.1186/1741-7015-8-71

23. Conselho Federal de Medicina. Resolução No 2.144/2016. É ético o médico atender à vontade da gestante de realizar parto cesariano, garantida a autonomia do médico, da paciente e a segurança do binômio materno fetal. Brasília, DF: CFM; 2016 [cited 1 May 2018]. Available from: https://portal.cfm.org.br/images/stories/pdf/res21442016.pdf

24. Agência Nacional de Saúde Suplementar. Resolução Normativa - RN No 368, de 6 de janeiro de 2015. Dispõe sobre o direito de acesso à informação das beneficiárias aos percentuais de cirurgias cesáreas e de partos normais, por operadora, por estabelecimento de saúde e por médico e sobre a utilização do partograma do cartão da gestante e da carta de informação à gestante no âmbito da saúde suplementar. Brasília, DF: ANS; 2015 cited 2 May 2018]. Available from: http://www.ans.gov.br/component/legislacao/?view=legislacao\&task=TextoLei\&format=raw \&id $=\mathrm{Mjg} 5 \mathrm{Mg}==$

25. Haddad SEMT, Cecatti JG. Estratégias dirigidas aos profissionais para a redução das cesáreas desnecessárias no Brasil. Rev Bras Ginecol Obstet. 2011;33(5):252-62. Portuguese. https://doi.org/10.1590/S0100-72032011000500008

26. Paris GF, Monteschio LVC, Oliveira RR, Latorre MRDO, Pelloso SM, Mathias TAF. Tendência temporal da via de parto de acordo com a fonte de financiamento. Rev Bras Ginecol Obstet. 2014;36(12):548-54. https://doi.org/10.1590/So100-720320140005038 
27. Esteves-Pereira AP, Deneux-Tharaux C, Nakamura-Pereira M, Saucedo M, Bouvier-Colle $\mathrm{MH}$, Leal MC. Caesarean delivery and postpartum maternal mortality: a population-based case control study in Brazil. PLoS One. 2016;11(4):e0153396. https://doi.org/10.1371/journal.pone.0153396

28. Mascarello KC, Horta BL, Silveira MF. Complicações maternas e cesárea sem indicação: revisão sistemática e meta-análise. Rev Saude Publica. 2017;51:105 https://doi.org/10.11606/s1518-8787.2017051000389

29. Say L, Chou D, Gemmill A, Tuncalp O, Moller AB, Daniels J, et al. Global causes of maternal death: a WHO systematic analysis. Lancet Glob Health. 2014;2(6):e323-33. https://doi.org//10.1016/ S2214-109X(14)70227-X

30. ACOG Committee on Practice Bulletins-Obstetrics. Practice Bulletin No. 183: postpartum hemorrhage. Obstet Gynecol. 2017;130(4):e168-86. https://doi.org/10.1097/AOG.0000000000002351

31. Vendemiatti M, Siqueira ES, Filardi F, Binotto E, Simioni FJ. Conflito na gestão hospitalar: o papel da liderança. Cienc Saude Coletiva. 2010;15 Suppl 1:1301-14. https://doi.org/10.1590/S1413-81232010000700039

32. Claro CM, Krocockz DVC, Toffolleto MC, Padilha KG. Eventos adversos em Unidade de Terapia Intensiva: percepção dos enfermeiros sobre a cultura não punitiva. Rev Esc Enferm USP. 2011;45(1):167-72. https://doi.org/10.1590/S0080-62342011000100023

33. Gouvêa CSD, Travassos C. Indicadores de segurança do paciente para hospitais de pacientes agudos: revisão sistemática. Cad Saude Publica. 2010;26(6):1061-78. https://doi.org/10.1590/S0102-311X2010000600002

34. Primo MGB, Guilarde AO, Martelli CMT, Batista LJA, Turchi MD. Healthcareassociated Staphylococcus aureus bloodstream infection: length of stay, attributable mortality, and additional direct costs. Braz J Infect Dis. 2012;16(6):503-9. https://doi.org/10.1016/j.bjid.2012.10.001

Authors' Contributions: Conceptualization and planning of the study: LMSL, ARB. Data collection, analysis and interpretation: LC, JFCP, TPRS, ASC, TGN. Elaboration or revision of the manuscript: TPRS, ASC, TGN, LLM, ADM, MCP, LC, JFCP, FPM. Approval of the final version: TPRS, ASC, TGN, LLM, ADM, MCP, LC, JFCP, FPM. Public responsibility for the content of the article: TPRS, ASC, TGN, LLM, ADM, MCP, LC, JFCP, FPM.

Conflict of Interest: The authors declare no conflicts of interest. 